\title{
Article \\ Challenges with Harmonic Compensation at a Remote Bus in Offshore Wind Power Plant
}

\author{
Sanjay Chaudhary ${ }^{1, \dagger *}$, Cristian Lascu ${ }^{1}$, Bakhtyar Hoseinzadeh ${ }^{1}$, Remus Teodorescu ${ }^{1}$, tukasz \\ Kocewiak $^{2}$, and Troels Sørensen ${ }^{2}$ \\ 1 Department of Energy Technology, Aalborg University, Fredrik Bajers Vej 5, 9100 Aalborg, Denmark; \\ skc@et.aau.dk, cla@et.aau.dk, ret@et.aau.dk, bho@et.aau.dk \\ 2 DONG Energy Wind Power, Fredericia, Denmark; lukko@dongenergy.dk, troels@dongenergy.dk \\ * Correspondence: skc@et.aau.dk; Tel.: +45-2137 1034 \\ + This paper is an extended version of our paper published in IEEE $16^{\text {th }}$ International Conference on \\ Environment and Electrical Engineering (EEEIC) 2016.
}

\begin{abstract}
The interaction between the grid network and the offshore wind power plant (WPP) network can lead to the amplification of certain harmonics and potentially resonant conditions. Offshore WPP should limit the increment of harmonic voltage distortion at the point of connection to the grid network as well as within their internal network. The harmonic distortion should be limited within the planning level limits using harmonic compensation, which is usually achieved by using static filters. In this paper an active damping compensation strategy with a STATCOM using emulation of resistance at the harmonic frequencies of concern is analysed. Such a compensation is effective for the local bus, though the performance is not guaranteed at the remote bus. This paper investigates the challenges associated with remote harmonic compensation in the offshore WPP, which is connected to the onshore grid through long high-voltage cables and transformers. First, the harmonic distortion and the compensating effects of the filter are theoretically assessed. Afterwards, they are demonstrated using harmonic propagation studies and time domain simulations in PSCAD.
\end{abstract}

Keywords: harmonic distortion; active power filter; resonance; damping; wind power plants

\section{Introduction}

Several large offshore wind power plants (WPP) have been installed in Europe and many more are under different stages of development. These usually comprise of type III or type IV wind turbines (WT) with power electronic converters and are connected to the ac network through High Voltage AC (HVAC) or High Voltage DC (HVDC) transmission systems. HVAC transmission systems are widely used in large scale WPPs closer to the shore, within 50-100 km from the shore [1], due to simple installation and maintenance, higher reliability and less complexity in comparison to HVDC systems. Anholt, Horns Rev and Nysted WPPs in Denmark and Barrow wind farm in United Kingdom are some of the WPPs HVAC connection to the grid [2,3].

HVAC connection of Offshore Wind Power Plants (WPPs) typically comprise of long submarine and underground HVAC cables up to the point of grid connection and step up transformers. Meanwhile, huge number of medium voltage (MV) submarine cables of network collection of wind turbines should not be overlooked. The combination of the transformer inductance and the submarine cable capacitance might produce a resonant circuit, which may cause amplification of harmonics [4]. Harmonic emission level of power electronic based generation sources should meet 
the requirements mentioned in the relevant standards including recommended (IEEE and IEC) and planning (G5/4-1) limits [5-7].

Power electronic converters and non-linear loads produce the major part of grid harmonics. Grid background harmonic at a particular terminal reflects the overall impact of aforementioned harmonic sources at that specific bus, e.g. the Point of Connection (POC). Existence of harmonics in the grid is inevitable even in the absence of WPP. Connection of WPP to the grid, influences the effective grid impedance at POC. Depending on the interaction between the WPP and grid impedances, there may be an amplification or an attenuation of the harmonic voltage distortion. New resonant modes may appear and/or the existing resonant modes may move to undesirable frequencies, thereby amplifying the harmonic distortion leading to poor power quality at the POC exceeding the permissible levels of harmonic distortion. Moreover, the injection of harmonics by built-in power electronic converters of WPPs, may also worsen the situation.

Current work addresses magnification of grid background harmonic due to the interaction between the WPP and grid impedances. The main focus is devoted to the grid background harmonics as the main source of harmonics and the share of Wind Turbines (WTs) in current harmonic injection is considered as future works. Later on, active damping of harmonics is performed by the emulation of resistive behaviour by the STATCOM at particular frequencies. The research findings confirm that the harmonic compensation is efficient at the local bus. However, its performance is not guaranteed at the remote buses. Due to practical considerations and current state of the art of STATCOM technology, the STATCOM is not connected to the high voltage buses (POC and PCC) close to the grid. To meet the requirements of grid codes associated with harmonics, the harmonic level should be within the limits specified at the PCC or POC which appear to be the remote bus with respect to the point of connection of the STATCOM. This paper investigates the challenges and difficulties in harmonic mitigation and compliance with the power quality at such remote buses.

This paper is organized as follows. The test WPP grid network is presented along with the mathematical analysis of the amplification or attenuation of harmonics and the effect of harmonic compensation in section 2. The effect of harmonic compensation upon the harmonic impedance of WPP network is illustrated in in section 3. The Nyquist criterion is applied to assess the overall stability of the compensation strategy in section 4 . The results of the harmonic propagation studies and time domain simulation are presented in section 5. Finally, the paper is concluded in section 6.

\section{Test WPP Grid Network}

\subsection{Wind power plant model}

The Anholt offshore WPP in Denmark with the capacity of 400 MW is chosen as a case study for harmonic study of WPP network as shown in Figure 1 [8]. Three step up transformers (3x140 MVA, 225/34 kV) connect the WPP collection network to the submarine cable. The submarine cable size and length are $3^{*} 1600 \mathrm{~mm}^{2}$ and $24.5 \mathrm{~km}$ respectively. It is connected to the underground cable $\left(3^{*} 2000 \mathrm{~mm}^{2}\right)$ with the length of $58 \mathrm{~km}$. The generated power is delivered to the onshore grid using two units of 450 MVA, $410 / 233 \mathrm{kV}$ transformers in parallel. Two switched shunt reactors (120 and 240 MVar) are employed to compensate the reactive power of cable capacitance in the submarine and underground cables, respectively. A STATCOM is connected to the $220 \mathrm{KV}$ bus, $T_{2}$ for the dynamic reactive power compensation as well as the active damping of resonance and mitigation of harmonic voltage distortion .

The medium voltage (MV) cables in the $34-\mathrm{kV}$ collector network of the WPP is collectively represented by 3 sets of $4 \times 11 \mathrm{~km}$ cable of $500 \mathrm{~mm}^{2}$ at $34 \mathrm{kV}$ voltage level. The capacitance of the MV cables is selected such that the overall capacitance of resultant cable network remains unchanged. 


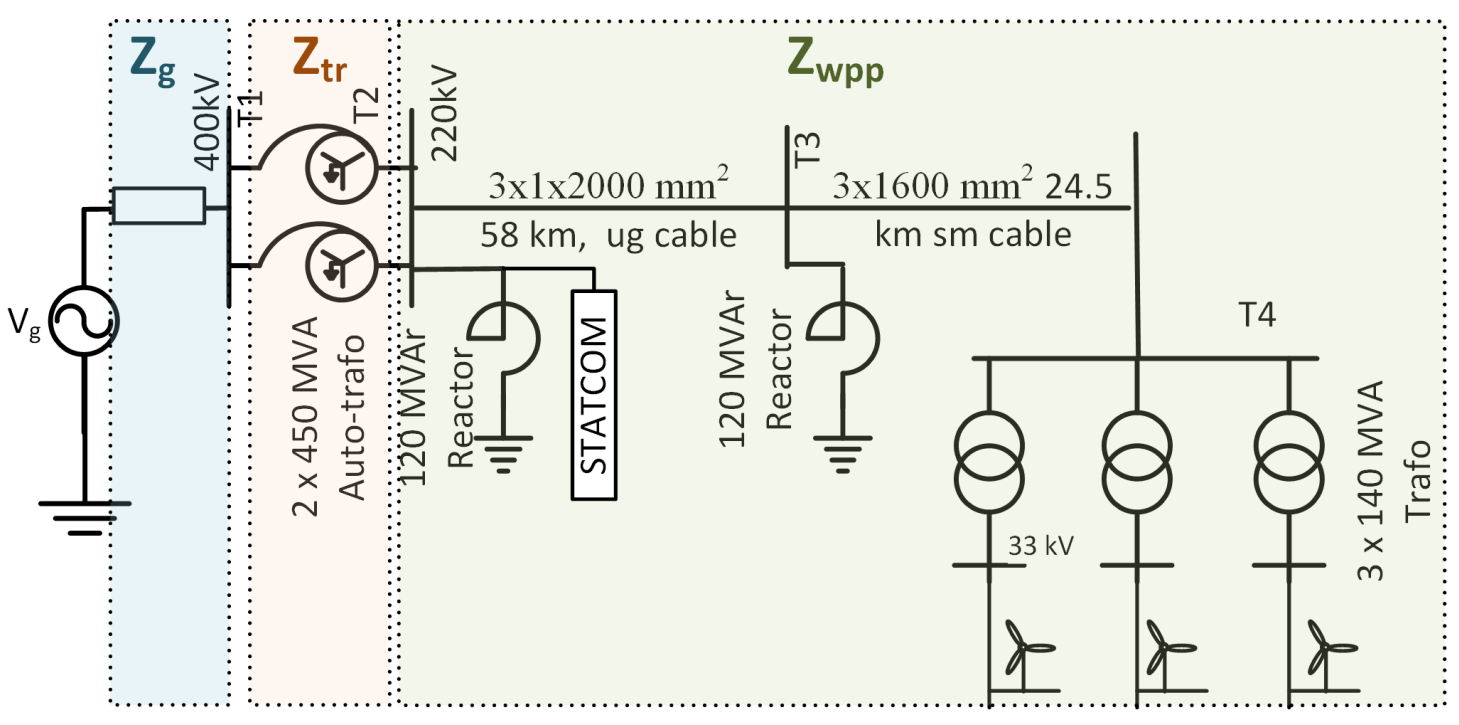

Figure 1. WPP electrical network model.

Table 1. Base Values.

\begin{tabular}{llcc}
\hline & Unit & Grid and at $T_{1}$ & At $T_{2}, T_{4}$, and HV Cables \\
\hline Power & {$[\mathrm{MW}]$} & 400 & 400 \\
RMS voltage & {$[\mathrm{kV}]$} & 400 & 220 \\
RMS current & {$[\mathrm{kA}]$} & 577.4 & 1049.7 \\
Resistance & {$[\Omega]$} & 400 & 121 \\
\hline
\end{tabular}

\subsection{Grid}

The main grid is modelled by three phase voltage sources with background voltage harmonics. The grid impedance is considered in series with the voltage source in accordance to the Thévenin equivalent circuit [9]. Figure 2-a represents the magnitude of voltage harmonics at the PCC and other buses $\left(T_{1}, T_{2}\right.$ and $\left.T_{4}\right)$. Figure 2-b indicates the current harmonic injected by the grid into the WPP in different locations. The bar values are shown in pu calculated according to the base values given in Table 1.

The frequency spectrum of grid impedance is available as magnitude and phase in term of frequency. Although, the aforementioned data can be directly utilized for frequency domain analysis, such as the harmonic propagation studies, it cannot be applied to the time domain simulation studies. In this case the data needs to be transformed to a frequency domain transfer function using vector fitting technique [10]. The frequency sweep data of grid impedance (actual grid impedance data) and the resultant Frequency Dependent Network Equivalent (FDNE) transfer function is shown in Figure 3. 

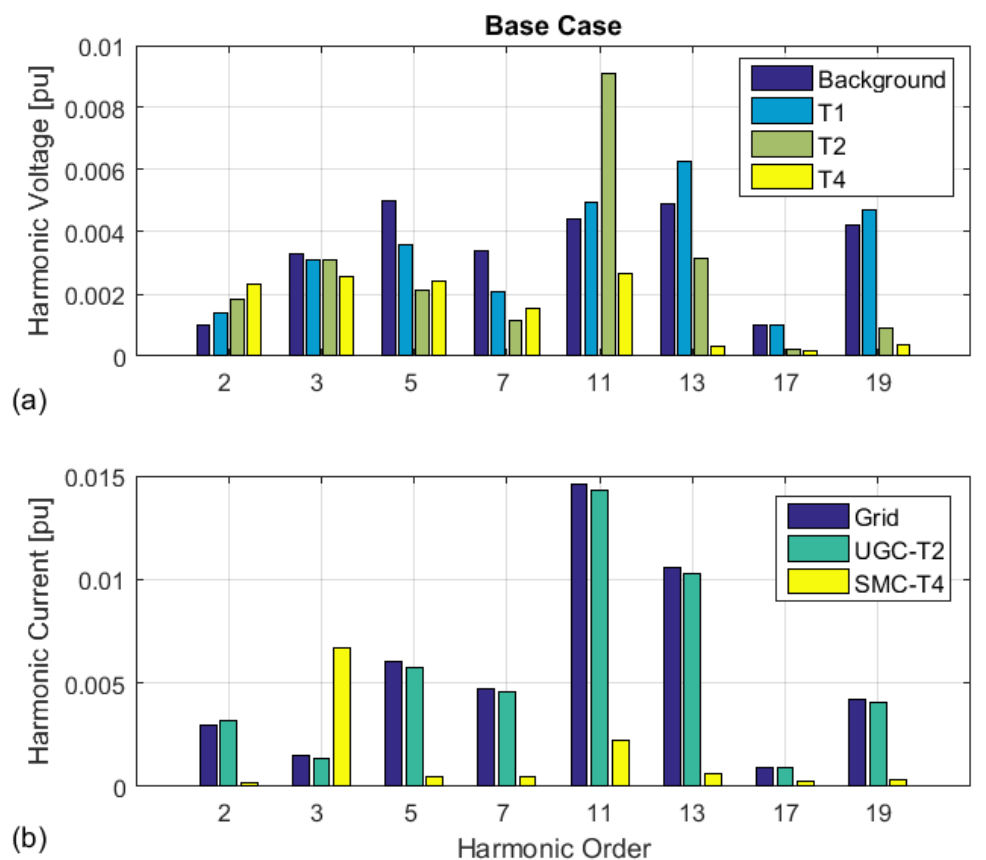

Figure 2. . Base case. (a) Background harmonic levels, and the harmonic voltages at $T_{1}, T_{2}$ and $T_{4}$, and (b) Harmonic current flow in the grid and the HV cables (UGC: underground cables and SMC:submarine cables) at $T_{1}, T_{2}$ and $T_{4}$. 

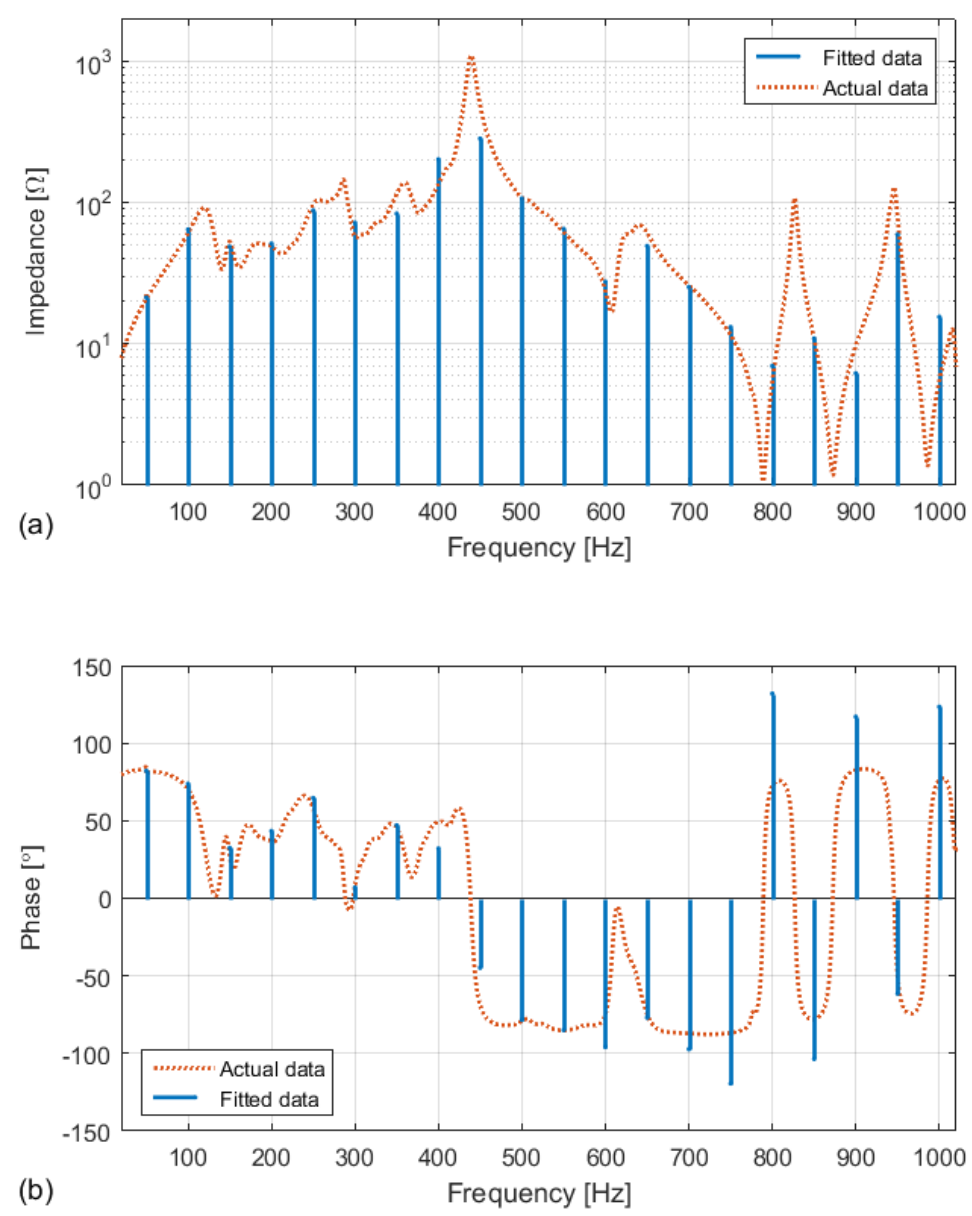

Figure 3. Grid impedance characteristics. (a) Magnitude, and (b) Phase angle.

95

\subsection{Amplification/Attenuation of harmonic distortion}

Magnification or attenuation of harmonics at different buses may happen due to the interaction between the grid impedance in series with the equivalent impedance of the WPP and its submarine, underground cables and collection network. In this study, the $400 \mathrm{kV}$ bus, i.e. $T_{1}$ is considered as PCC, and thus the objective is to reduce the harmonic distortion at bus $T_{1}$.

By excluding the harmonic emission of WTs and considering the grid as the main source of harmonic distortion, the amplification of harmonic voltage distortion at buses $T_{1}$ and $T_{2}$ are given by:

$$
\left.\begin{array}{l}
A_{1}=\frac{V_{1 h}}{V_{g h}}=\frac{Z_{t r, h}+Z_{w p p, h}}{Z_{g, h}+Z_{t r}, h+Z_{w p p, h}} \\
A_{2}=\frac{Z_{w w p}}{V_{g h}}=\frac{Z_{w p h}}{Z_{g, h}+Z_{t r, h}+Z_{w p p, h}}
\end{array}\right\},
$$

96 where, $Z_{t r, h}, Z_{w p p, h}$ and $Z_{g, h}$ are the impedance of transformer, WPP and the grid at the $h^{\text {th }}$ harmonic 97 order represented in Figure 4 . The amplification ratios $A_{1}$ and $A_{2}$ in (1) versus frequency are plotted 98 in Figure 5. Values greater/smaller than one is interpreted as amplification/attenuation. At bus $T_{1}$, 99 the harmonic orders $2^{\text {nd }}, 9-15^{\text {th }}, 17^{\text {th }}$ and the $19^{\text {th }}$ are amplified. At bus $T_{2}$, the $2^{\text {nd }}, 11^{\text {th }}$ and the $12^{\text {th }}$ harmonic orders are amplified. 


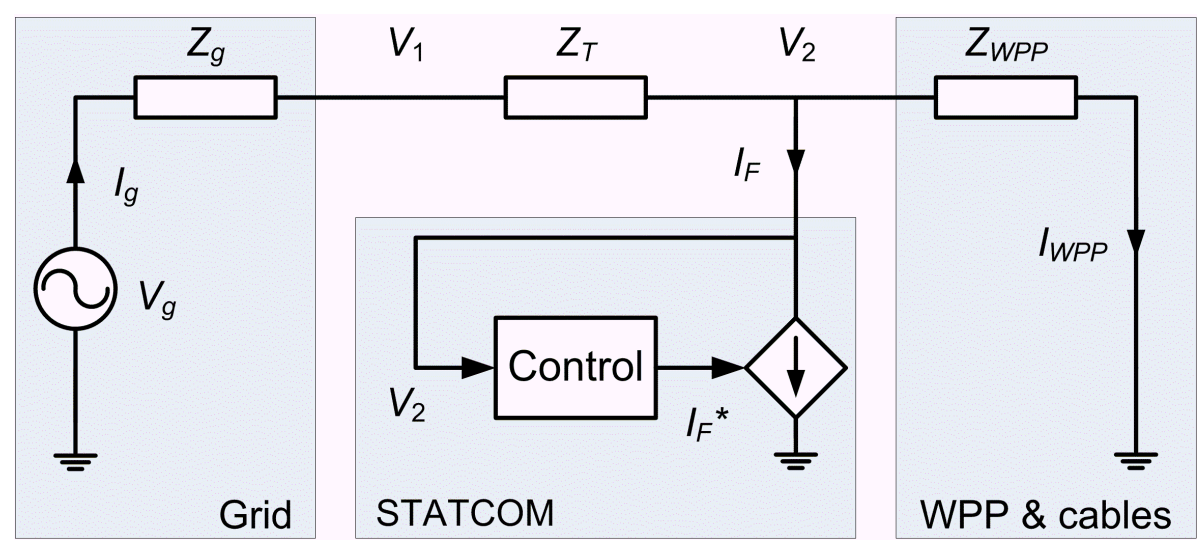

Figure 4. An equivalent single line drawing of the test system.

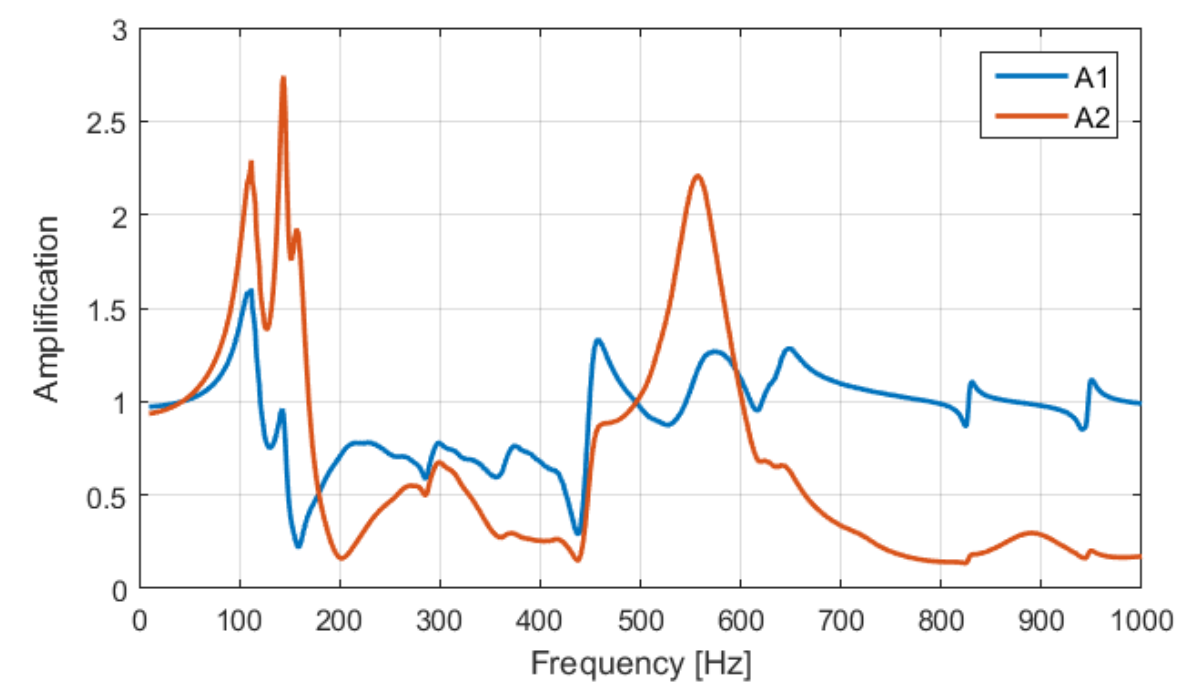

Figure 5. Amplification of the background harmonics in the grid.

The amplification of $13^{\text {th }}$ harmonic order at $T_{1}$ by 1.27 times makes sense due to the positive sequence impedance values of, $Z_{g, 13}=(17-j 59) \Omega$ on the grid side and $\left(Z_{t r, 13}+Z_{\text {wpp }, 13}\right)=(48+j 233) \Omega$ on the WPP side at the bus $T_{1}$ when referred to the $400 \mathrm{kV}$ voltage base. Typically, the odd harmonics at the $5^{\text {th }}, 7^{\text {th }}, 11^{\text {th }}, 13^{\text {th }}, 17^{\text {th }}$ and $19^{\text {th }}$ have a relatively higher content in the background harmonics in the grid. Hence, the amplification of these harmonics should be checked to the extent feasible.

\subsection{STATCOM controller for harmonic compensation}

When a resistor is connected in shunt, it reduces the overall impedance and hence the voltage drops. However, it would affect the harmonic as well as the fundamental frequency components. Moreover, it leads to high losses and hence connecting a resistor for harmonic compensation is not feasible. It is therefore emulated by a STATCOM, which provides reactive power compensation at the fundamental frequency and selective harmonic filtering. Figure 6 shows the block diagram of the STATCOM controller for the active power filter (APF) functionality. It will be in addition to the reactive power regulation, which happens at the fundamental frequency. The aspect of reactive power compensation is not described in this paper. 


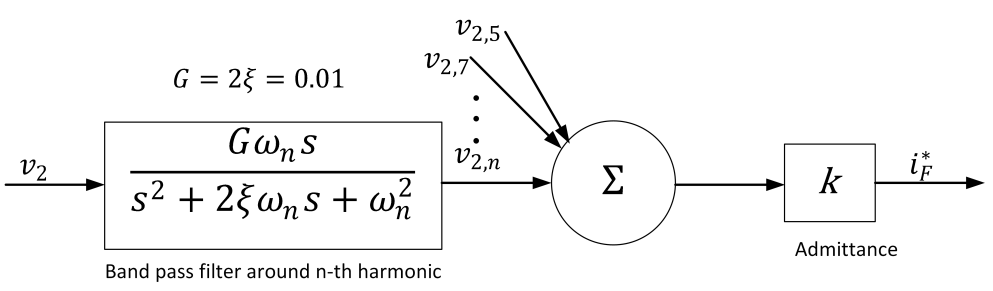

Figure 6. STATCOM controller for harmonic compensation.

The terminal voltage $v_{2}$ is measured at $T_{2}$ and the harmonic components are extracted using band-pass filters tuned around the desired harmonic frequency orders. Afterwards, the harmonic components are added together and multiplied by a constant admittance, $k$, to produce the harmonic current reference, $i_{F}^{*}$ to provide the harmonic compensation. The individual band pass filter around the harmonic frequency, $\omega_{n}$, has the transfer function,

$$
H F_{n}(s)=\frac{G \cdot \omega_{n} \cdot s}{s^{2}+2 \cdot \xi \cdot \omega_{n} \cdot s+\omega_{n}^{2}} .
$$

Such a filter is required for each of the individual harmonic orders concerned. Therefore, the resultant filter transfer function is,

$$
H F(s)=\sum_{n}^{N} \frac{2 \cdot \xi \cdot \omega_{n} \cdot s}{s^{2}+2 \cdot \xi \cdot \omega_{n} \cdot s+\omega_{n}^{2}}
$$

The frequency vs. magnitude and phase characteristic of the multiple harmonic band-pass filters in parallel are shown in Figure 7. Here the individual filter characteristics are shown by the curves for the legends $G_{n}$, where the subscript $n$ denotes the corresponding harmonic order. The thick curve for the legend $H$ indicates the overall combination of all six harmonic filters used in this work. Once the harmonic components are extracted, the harmonic current reference is given by (4),

$$
I_{f, h}(s)=k \cdot H F(s) \cdot V_{2, h}(s),
$$

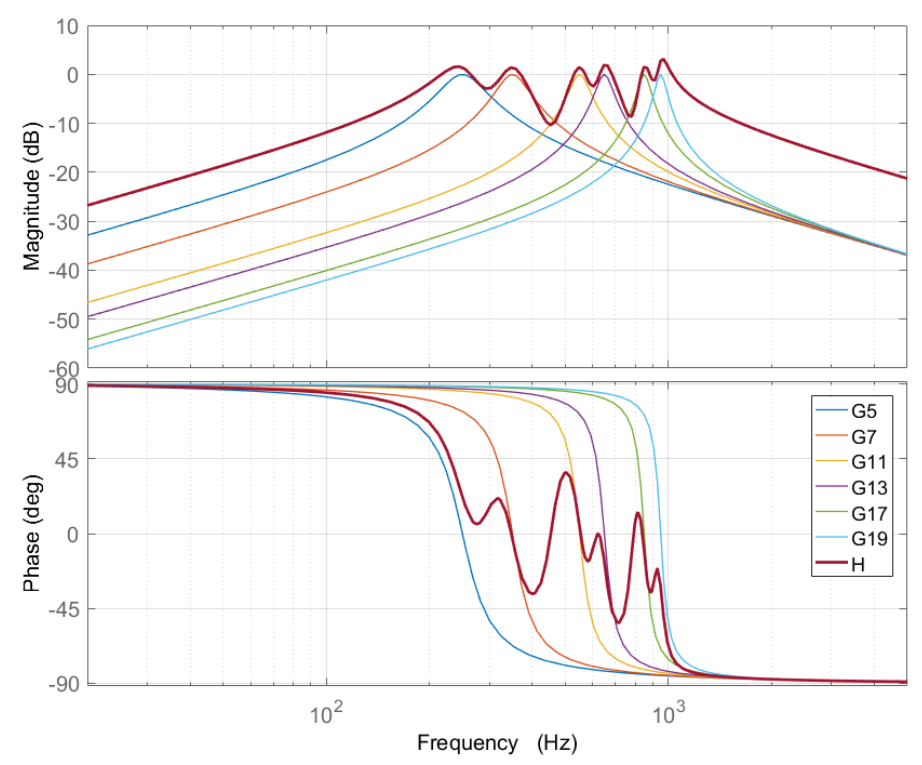

Figure 7. Bode plot of the individual harmonic filter transfer functions and their parallel combination. 
where, $k$ has the unit of admittance. It may be the same for all the desired harmonic orders, or different for each of the different harmonic components. Thus, the current references are proportional to the corresponding harmonic voltages. Since $k$ is a real constant number, the emulated impedance is resistive.

Applying the superposition theorem, the resultant harmonic voltage at the terminal $T_{2}$ due to the background harmonic voltage in the grid, $V_{g, h}(s)$, and the harmonic current, $I_{g, h}(s)$, drawn by the STATCOM as shown in Figure 4, is given by,

$$
V_{2, h}(s)=\frac{Z_{w p p, h}(s) \cdot V_{g, h}(s)-Z_{w p p, h}(s) \cdot\left(Z_{g, h}+Z_{t r, h}(s)\right) \cdot I_{f, h}(s)}{Z_{\Sigma}(s)},
$$

where, $Z_{\Sigma}(s)=Z_{g, h}(s)+Z_{t r, h}(s)+Z_{w p p, h}(s)$. Substituting the harmonic current reference from (4),

$$
V_{2, h}(s)=\frac{Z_{w p p, h}(s) \cdot V_{g, h}(s)}{Z_{\Sigma}(s) \cdot\left(1+\frac{k \cdot H F(s) \cdot Z_{w p p, h}(s) \cdot\left(Z_{g, h}(s)+Z_{t r, h}(s)\right)}{Z_{\Sigma}(s)}\right)} .
$$

Thus, in comparison to the base case (i.e. without any compensation) the harmonic voltage is changed by a factor of,

$$
F_{2, h}(s)=\left(1+\frac{k \cdot H F(s) \cdot Z_{w p p, h} \cdot\left(Z_{g, h}+Z_{t r, h}\right)}{Z_{\Sigma}}\right)
$$

Since, the harmonic voltage at $T_{1}$ is given by,

$$
V_{1, h}(s)=\frac{Z_{t r, h}(s) \cdot V_{g, h}(s)-Z_{g, h}(s) \cdot V_{2, h}(s)}{Z_{g, h}(s)+Z_{t r, h}(s)}
$$

Using (6), (7) and (8), we get,

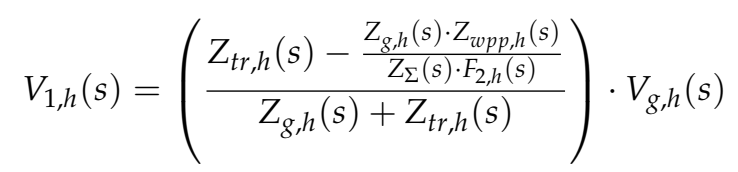

\section{Harmonic compensation analysis}

The WPP network is largely a radial network. When a compensating resistor is connected at a bus, the equivalent impedance of the network, downstream from that bus, decreases. Thus the system impedance characteristic gets changed. Consequently, the harmonic voltages at different buses in the system would change. The resultant amplification ratios for different cases with two different values of the harmonic filtering resistance connected at two different buses are numerically analyzed using (1).

\subsection{Active damping using harmonic resistance at bus $T_{2}$}

When a resistance is connected at $T_{2}$, it is in parallel to the WPP impedance. Hence, the effective WPP impedance is lower in magnitude and its phase angle moves closer to $0^{\circ}$,implying that it is more resistive as shown in Figure 8. The solid arrows indicate the $5^{\text {th }}, 11^{\text {th }}$ and the $13^{\text {th }}$ harmonic impedance when there is no compensation. The dotted lines indicate the locus of the tip of the impedance move from the initial uncompensated values towards the origin, as the emulated resistance is decreased from $10 \mathrm{pu}$ to $0.03 \mathrm{pu}$. The asterisk marks indicate the points for 2, 1.5, 1, 0.5, $0.25 \mathrm{pu}$ resistive compensation.

Physically, the resistors in harmonic power filters dissipate energy, and thus provide damping to harmonic amplifications. Likewise, the APF can provide damping to harmonic amplifications by 
emulating resistive behaviour at the selected harmonic frequencies [11]. This is the case for providing harmonic compensation at the local bus.

For the frequency domain analysis, a shunt resistor is connected at bus $T_{2}$, in parallel to the WPP impedance, $Z_{\text {wpp }}$. The resultant amplifications at bus $T_{1}$ and bus $T_{2}$ are shown in Figure 10. These curves show that while the compensation works for the full range of harmonics at bus $T_{2}$, it is not effective at the remote bus $T_{1}$ as the $6^{\text {th }}, 7^{\text {th }}, 10^{\text {th }}$, and $11^{\text {th }}$ harmonic voltages get amplified.
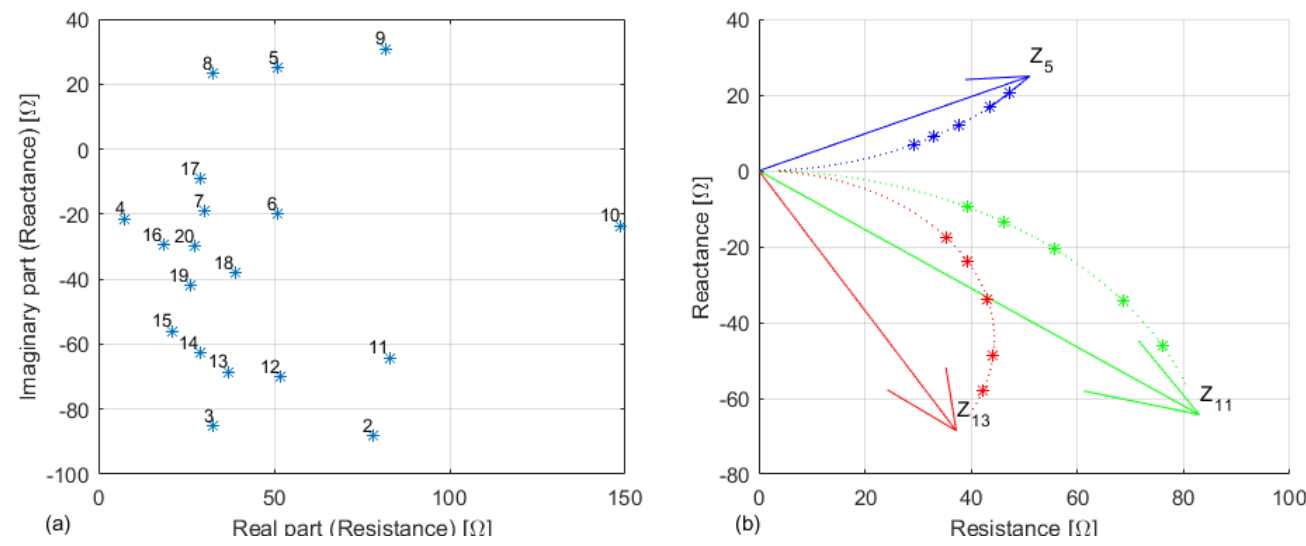

Figure 8. WPP impedance at $T_{2}$. (a) Impedance values at different harmonic orders. (b) $5^{\text {th }}, 11^{\text {th }}$ and $13^{\text {th }}$ order Impedance locus as the compensating resistance at $T_{2}$ is decreased from $10 p u$ to $0.03 p u$ $(1 p u=121 \Omega)$
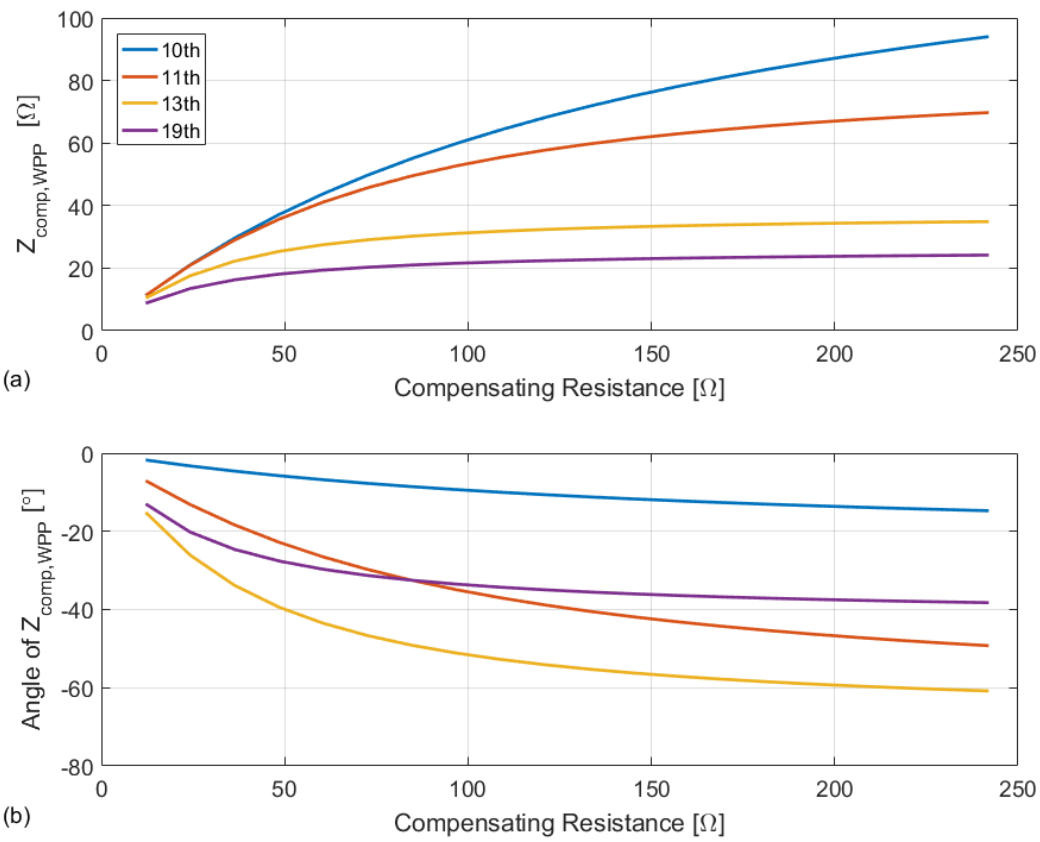

Figure 9. Variation of WPP impedance with resistance connected at $T_{2}$. (a) Magnitude. (b) Phase.

As shown in Figure 10, the harmonic compensation, provided by the resistances of sizes 1 pu $(121 \Omega)$ and $0.5 \mathrm{pu}(62.5 \Omega)$ respectively at bus $T_{2}$, reduces the local amplification ratio. However, it is not the same for the remote bus, $T_{1}$, which is upstream. An amplification is observed here, in the base case, as the grid impedance is capacitive while the WPP side impedance is inductive largely 
due to the inductive impedance of the grid transformers. Even though there is an attenuation of the $10^{\text {th }}$ harmonic at the local bus $T_{2}$, it gets amplified in comparison to the base case at $T_{1}$. This can be attributed to the reduced damping due to the reduction of the effective resistance of the WPP from $424 \Omega$ to $210 \Omega$ and due to the compensation as shown in Table 2.
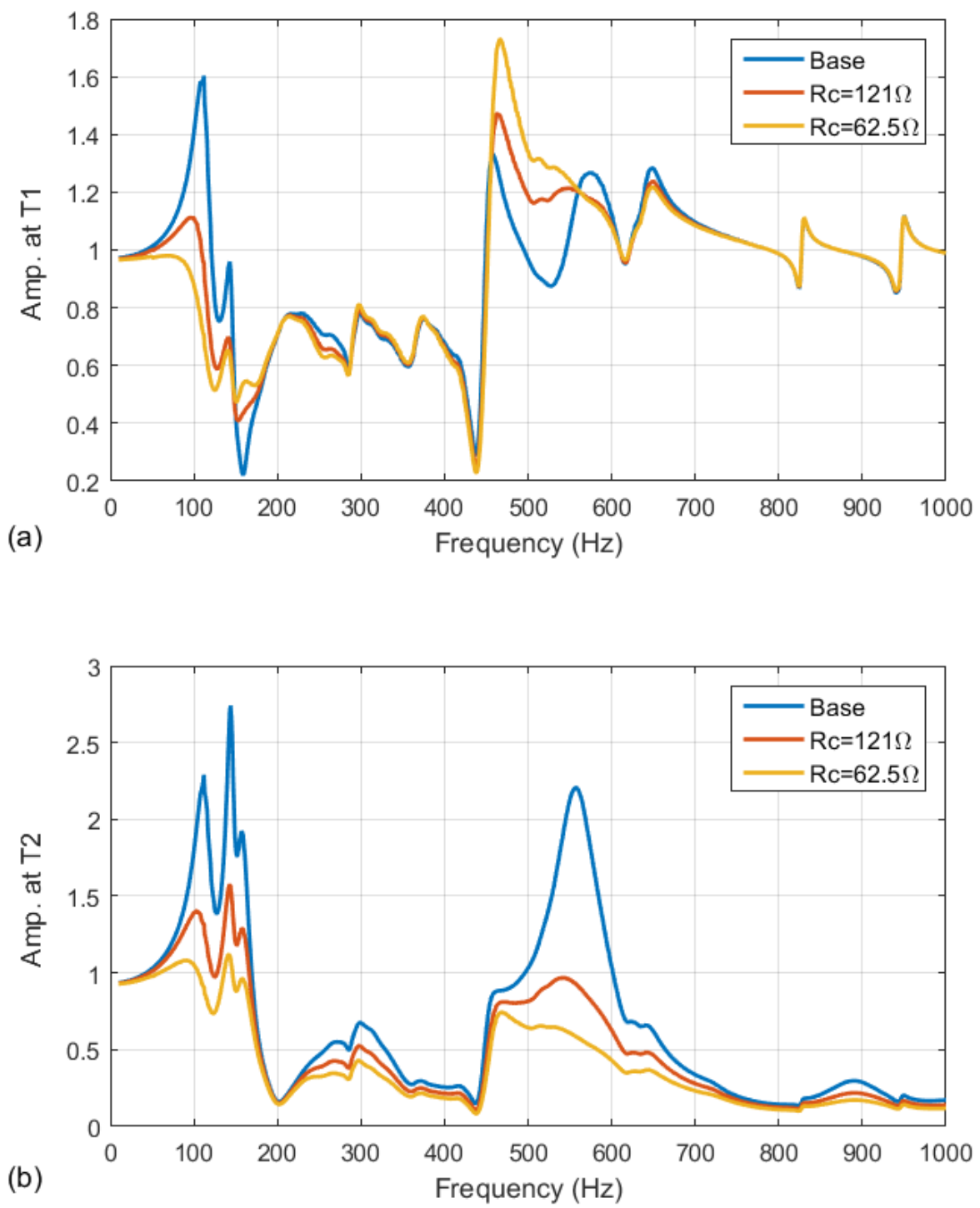

Figure 10. Amplification due to compensation at $T_{2}$.

Table 2. $10^{\text {th }}$ harmonic impedance (referred to $400 \mathrm{kV}$ ) observed at $T_{1}$ with $1 p u$ resistive compensation at $T_{2}$.

\begin{tabular}{lccc}
\hline & Unit & Real & Imaginary \\
\hline$Z_{g}$ & {$[\Omega]$} & 20 & -108 \\
$Z_{t r}$ & {$[\Omega]$} & 3 & 261 \\
$Z_{w p p}$ & {$[\Omega]$} & 421 & -185 \\
$Z_{w p p, c o m p}$ & {$[\Omega]$} & 207 & -39 \\
$Z_{w p p}+Z_{t r}$ & {$[\Omega]$} & 424 & 76 \\
$Z_{w p p, c o m p}+Z_{t r}$ & {$[\Omega]$} & 210 & 222 \\
\hline
\end{tabular}




\subsection{Active damping using harmonic resistance at bus $T_{1}$}

As shown in Figure 11, when the harmonic compensating resistances of sizes 1 pu (i.e. $400 \Omega$ ) and $0.5 \mathrm{pu}$ (i.e. $200 \Omega$ ) respectively are connected at bus $T_{1}$, the harmonic voltage gets reduced for the local bus $T_{1}$ as well as bus $T_{2}$, which lies downstream. It is expected, as the harmonic voltages are appearing due to background harmonics in the grid.
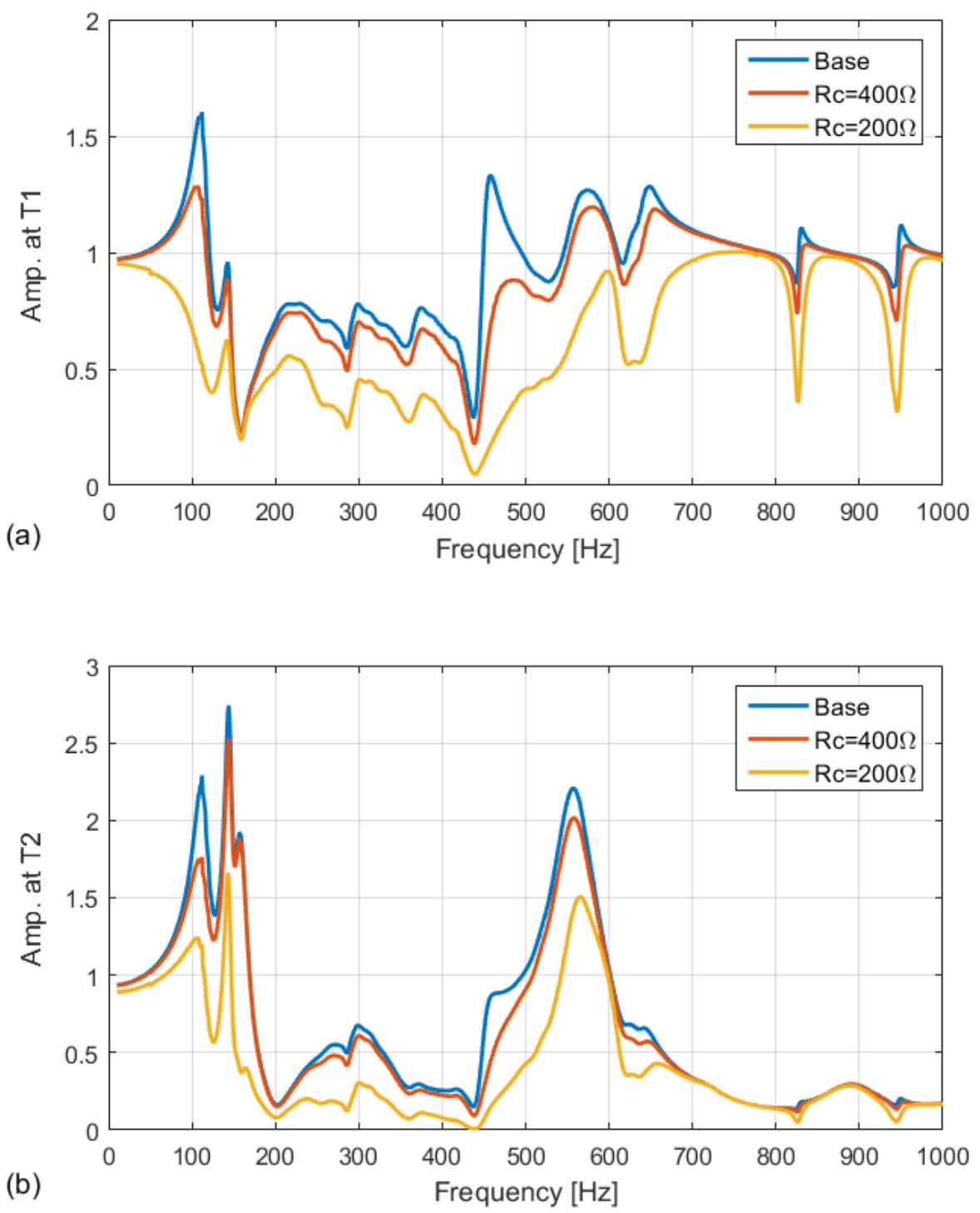

Figure 11. Amplification due to compensation at $T_{1}$.

\section{Nyquist Stability Analysis}

Equation (7) for the harmonic voltage reduction factor is analogous to the characteristic equation of a closed loop transfer function. Therefore, the stability of the proposed control algorithm can be studied using Nyquist stability criterion on the loop gain,

$$
F_{o l}(s)=\frac{k \cdot H F(s) \cdot Z_{w p p, h} \cdot\left(Z_{g, h}+Z_{t r, h}\right)}{Z_{\Sigma}} .
$$

If all the poles of (10) are on the right half plane, it will be stable for all values of the scalar gain constant $k$. The Nyquist plot of this factor shown in Figure 12. It appears to be stable for all positive 
values of $k$ as it does not encircle the point $(-1.0,0)$. The frequency characteristics of the harmonic voltage reduction factor is further elaborated in Figure 13. The phase margin at the gain crossover frequency of $240 \mathrm{rad} / \mathrm{sec}$ i.e. $38.2 \mathrm{~Hz}$ is $5 \mathrm{deg}$. This implies that there will be amplification of the frequency components less than $38 \mathrm{~Hz}$. The phase always remains within $\pm 180 \mathrm{deg}$.

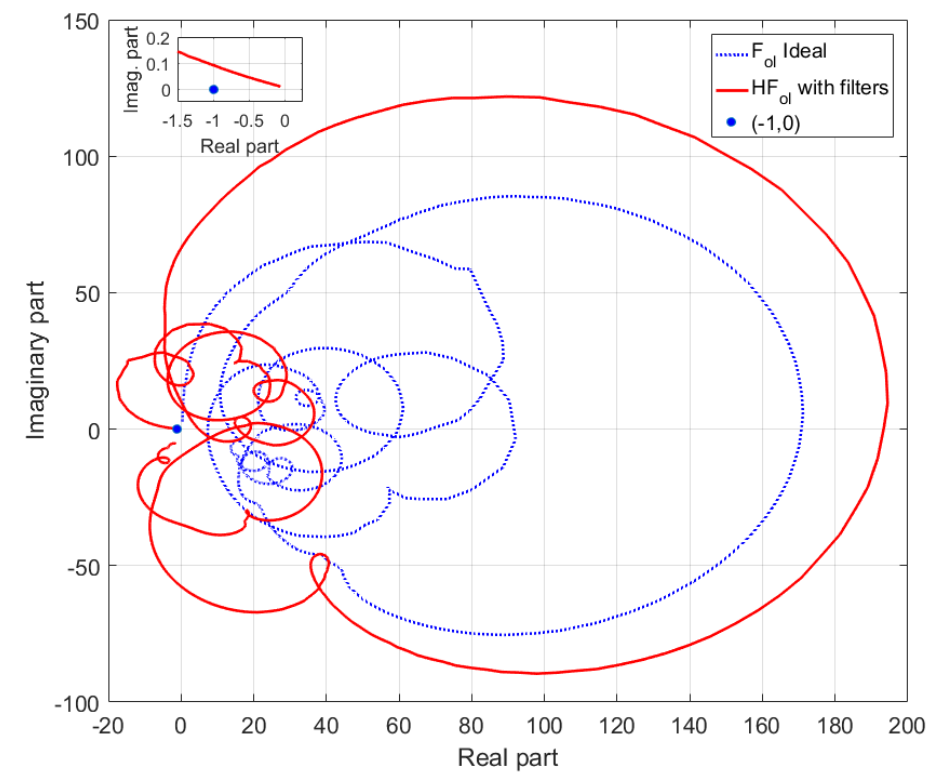

Figure 12. Nyquist plot of the harmonic resistance emulation.

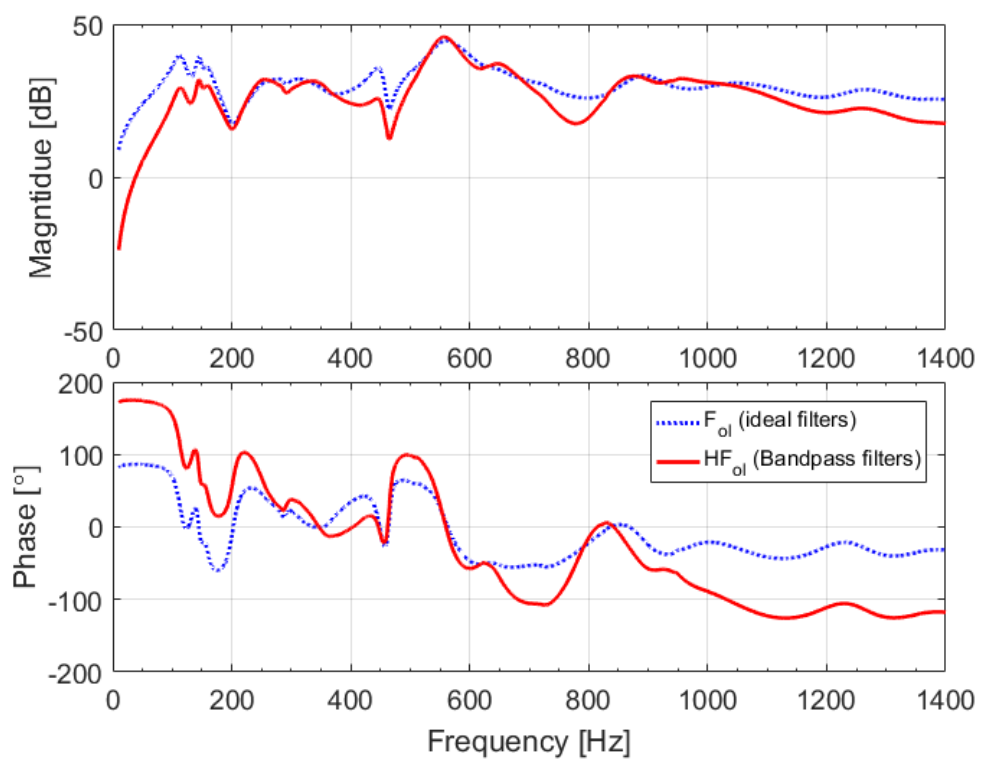

Figure 13. Bode plot of the of the harmonic voltage reduction factor at $T_{2}$.

\section{Simulation Results}

Harmonic propagation studies [12] is used to compare the harmonic voltage levels at different buses and harmonic currents through different components in the system. Afterwards, the performance of dynamic harmonic compensation is shown using time domain simulation in PSCAD. 


\subsection{Harmonic propagation studies}

In harmonic propagation studies, the network model is created for a specific harmonic frequency and the network equations are solved for that particular frequency. Since the power frequency is not considered and only one frequency is considered at a time, the emulation of resistance at the specific harmonic frequency by the STATCOM is simulated by a connecting a resistance in the network at the concerned bus. In this work, a 1-pu resistance is separately connected to bus $T_{1}$ and $T_{2}$. The resultant harmonic voltages at buses $T_{1}, T_{2}$ and $T_{4}$ are observed in the test system. The results are then compared in Figure 14. In line with the amplification ratios described in the previous section, the compensation at bus $T_{1}$ leads to a reduction of voltage harmonics at all the aforementioned buses. The compensation at bus $T_{2}$ leads to the reduction of harmonics at bus $T_{2}$ and $T_{4}$, which are downstream, while there is an amplification of the $7^{\text {th }}$ and the $11^{\text {th }}$ harmonic at bus $T_{1}$. The results corroborate the prediction made in the previous section as the distortion levels at bus $T_{2}$ is decreased for all the harmonic orders, whereas, for bus $T_{1}$, it gets decreased only for the $5^{\text {th }}$ and the $13^{\text {th }}$ harmonic orders.

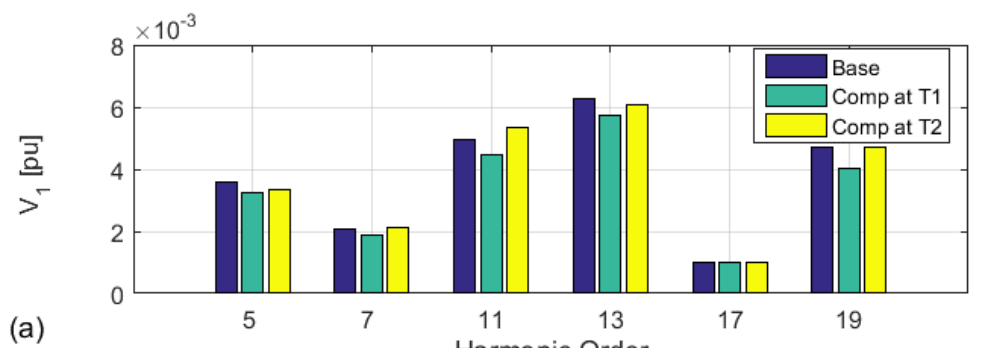

(a)

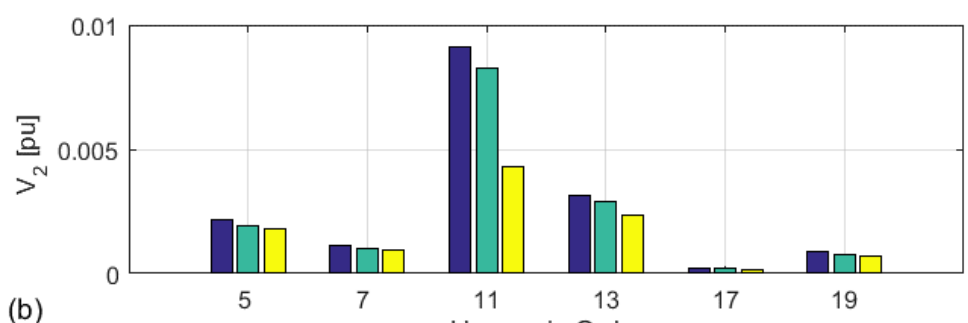

(b)

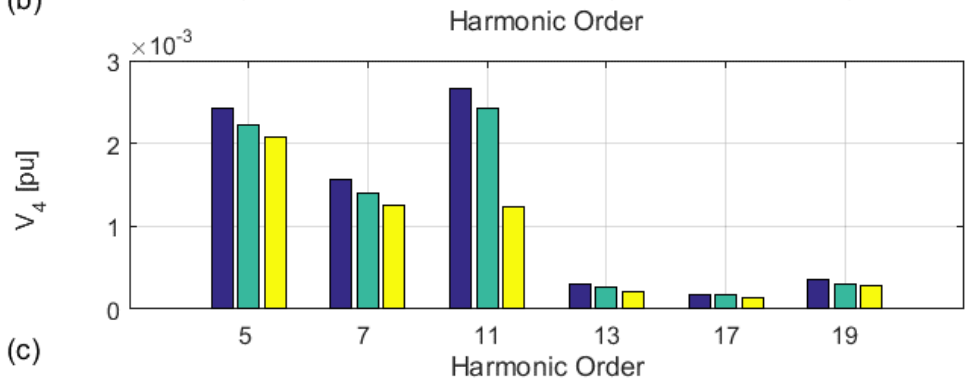

Figure 14. Harmonic voltages in pu at (a) $T_{1},(\mathbf{b}) T_{2}$, and (c) $T_{4}$.

The harmonic current flow in the different components as well as in the STATCOM is shown in Figure 15. The harmonic current drawn from the grid is higher than that in the base case, when the compensation is provided at bus $T_{1}$. By Kirchhoff's law, it is obvious that the grid has to supply the current drawn by the WPP as well as the compensating resistance. Thus, the resultant harmonic current in the grid will be the phasor sum of the WPP current and the STATCOM current. When the compensation is provided at bus $T_{2}$, the grid currents are reduced by over $50 \%$ for the $11^{\text {th }}$ harmonic, while there is a smaller reduction for other harmonics, except the $5^{\text {th }}$ harmonic, for which there is an amplification. This amplification is due to the reduction of the total impedance for the $5^{\text {th }}$ harmonic. 

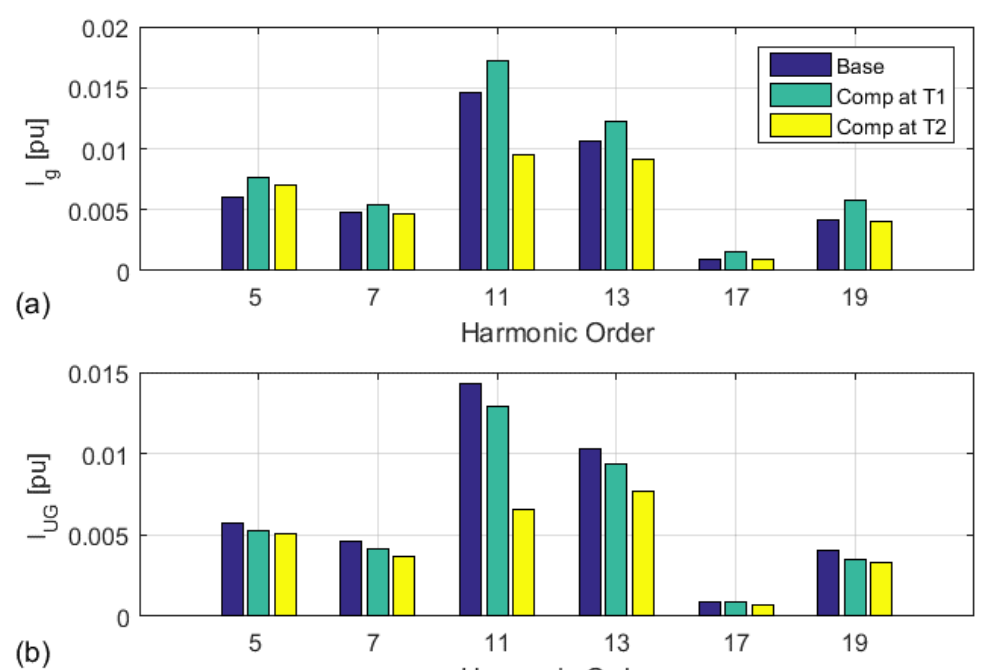

(b)

Harmonic Order
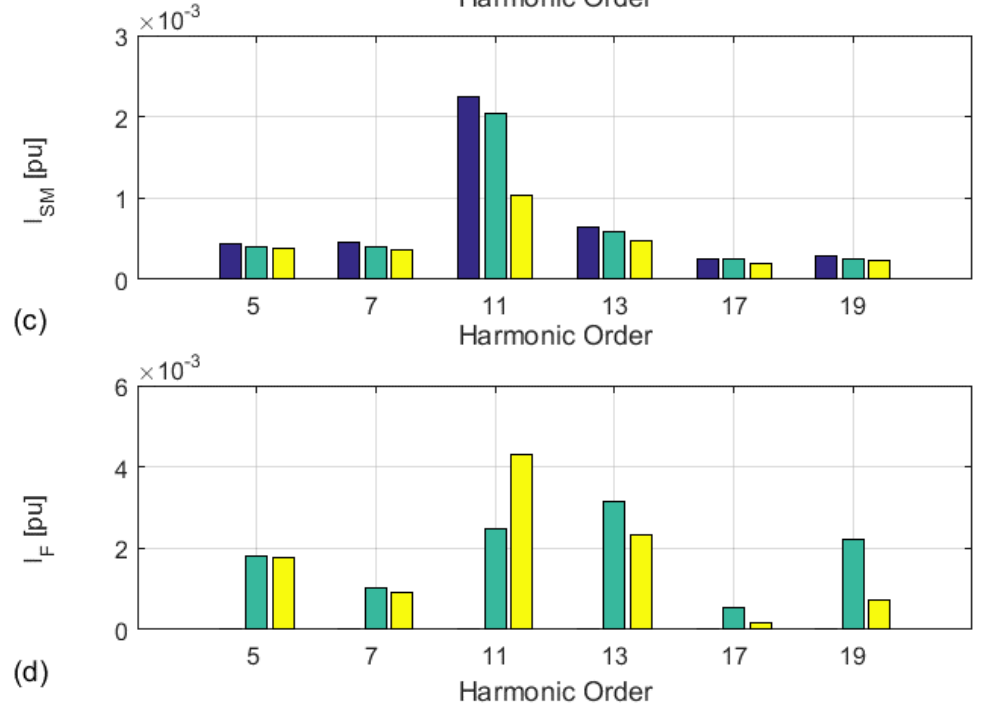

Figure 15. Harmonic currents in pu. (a) Grid at $T_{1}$, (b)Underground (UG) cable at $T_{2}$, (c) Sub-marine (SM) cable at $T_{4}$ and (d) STATCOM.

\subsection{Time domain simulation}

A time domain simulation model has been developed in PSCAD to show the STATCOM controller emulating the resistive behavior. The harmonic current source model of the STATCOM is connected to bus $T_{2}$ as shown in Figure 4. Its controller measures the $T_{2}$ bus voltage and extracts the $5^{\text {th }}, 7^{\text {th }}, 11^{\text {th }}, 13^{\text {th }}$, and the $19^{\text {th }}$ harmonic voltages. Then the corresponding harmonic current references are generated. When the voltage and currents are stated in $p u$ values, setting the gain $k=1$ results in the emulation of $1 p u$ resistance (i.e. $121 \Omega$ ) at the selected harmonics.

The harmonic filtering functionality of the STATCOM is activated at 5s. The dynamics of the $5^{\text {th }}$ and $11^{\text {th }}$ order harmonic voltages and the filter currents at $T_{1}$ and $T_{2}$ are shown in Figure 16 and Figure 17. The harmonic components of the voltage decrease at the local bus $T_{2}$. The $5^{\text {th }}$ harmonic component of the voltage at the local terminal $T_{2}$ decrease from $0.34 \%$ to $0.29 \%$. Similarly the $11^{\text {th }}$ harmonic component decrease from $1.42 \%$ to $0.64 \%$. The $5^{\text {th }}$ and $5^{\text {th }}$ harmonic currents from the STATCOM is $0.22 \%$ and $0.44 \%$ respectively. Table 3 shows that all the 5 selected harmonic voltage components get attenuated at the local bus $T_{2}$ due to the compensating harmonic currents from the STATCOM. The total rms value of the selected harmonic compensating currents is $0.57 \%$ of the nominal. 
For the remote bus $T_{1}$, the $5^{\text {th }}$ and the $13^{\text {th }}$ harmonic orders show attenuation while the $7^{\text {th }}$ and the $11^{\text {th }}$ orders get amplified as shown in Table 3 . The attenuation of the $5^{\text {th }}$ harmonic voltage component from $0.43 \%$ to $0.40 \%$ and the amplification of the $11^{\text {th }}$ harmonic voltage component from $0.47 \%$ to $0.51 \%$ as a result of the compensation from the STATCOM is shown in Figure 17. Though the numerical values intime domain simulation differ from the numbers obtained in the harmonic propagation studies, they exhibit similar trend.

Table 3. Harmonic voltages in the base case and after compensation (pu values are shown in percentage to reduce the leading zeros).

\begin{tabular}{lccccc}
\hline Harmonic order & 5th & 7th & 11th & 13th & 19th \\
\hline Bus $T_{1}$ & & & & & \\
\hline Base (\%) & 0.43 & 0.23 & 0.47 & 0.60 & 0.47 \\
Compensated (\%) & 0.40 & 0.23 & 0.52 & 0.58 & 0.47 \\
Change (\%) & 7 & -1 & -11 & 2 & 0 \\
\hline Bus $T_{2}$ & & & & & \\
\hline Base (\%) & 0.34 & 0.12 & 1.42 & 0.25 & 0.06 \\
Compensated (\%) & 0.29 & 0.09 & 0.64 & 0.21 & 0.05 \\
Change (\%) & 16 & 19 & 55 & 18 & 12 \\
Current (IF in \%) & 0.22 & 0.10 & 0.44 & 0.24 & 0.06 \\
\hline
\end{tabular}
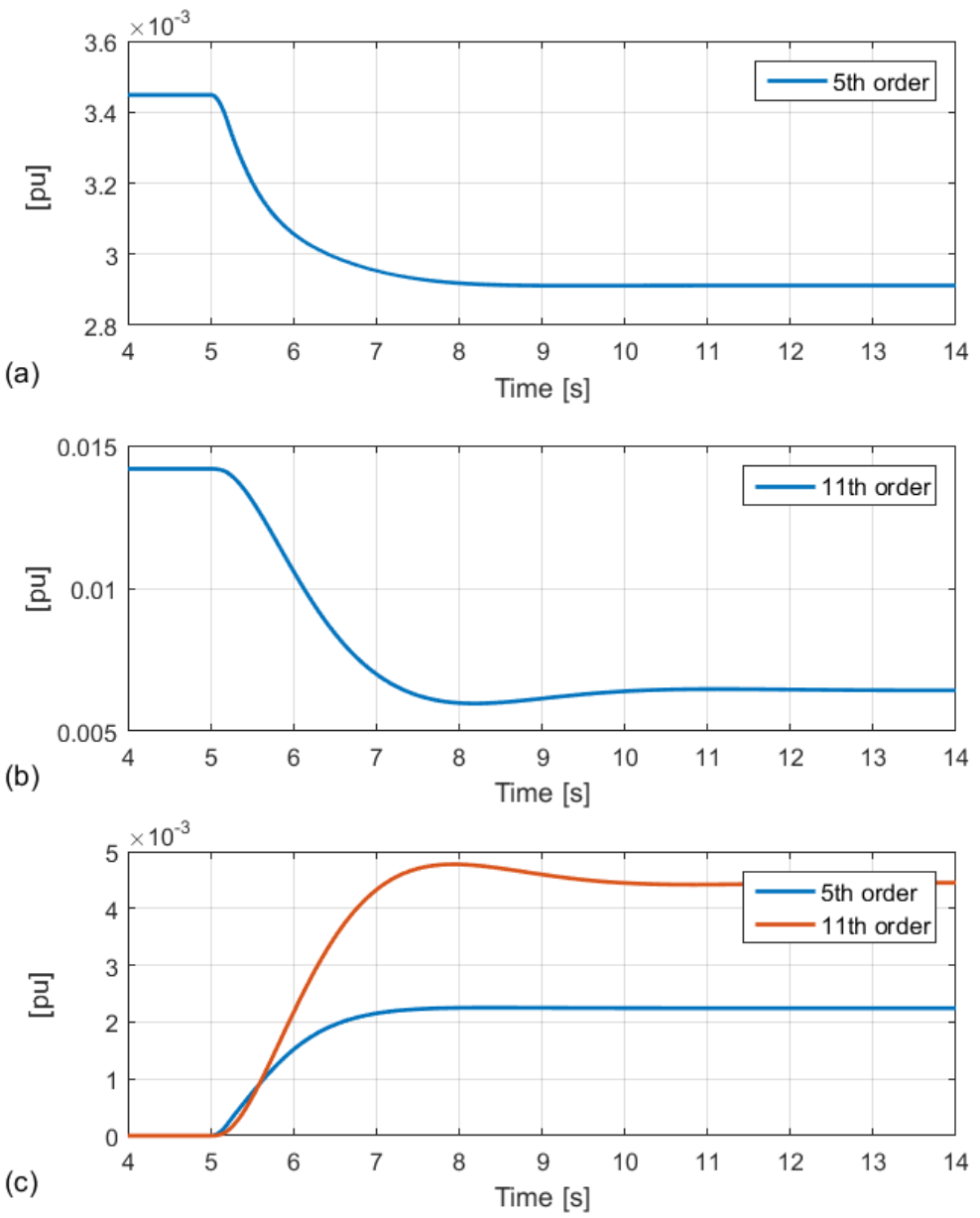

Figure 16. (a) $5^{\text {th }}$ harmonic voltage at $T_{2}$. (b) $11^{\text {th }}$ harmonic voltage at $T_{2}$. (c) $5^{\text {th }}$ and $11^{\text {th }}$ harmonic resistive currents by the STATCOM. 
(a)
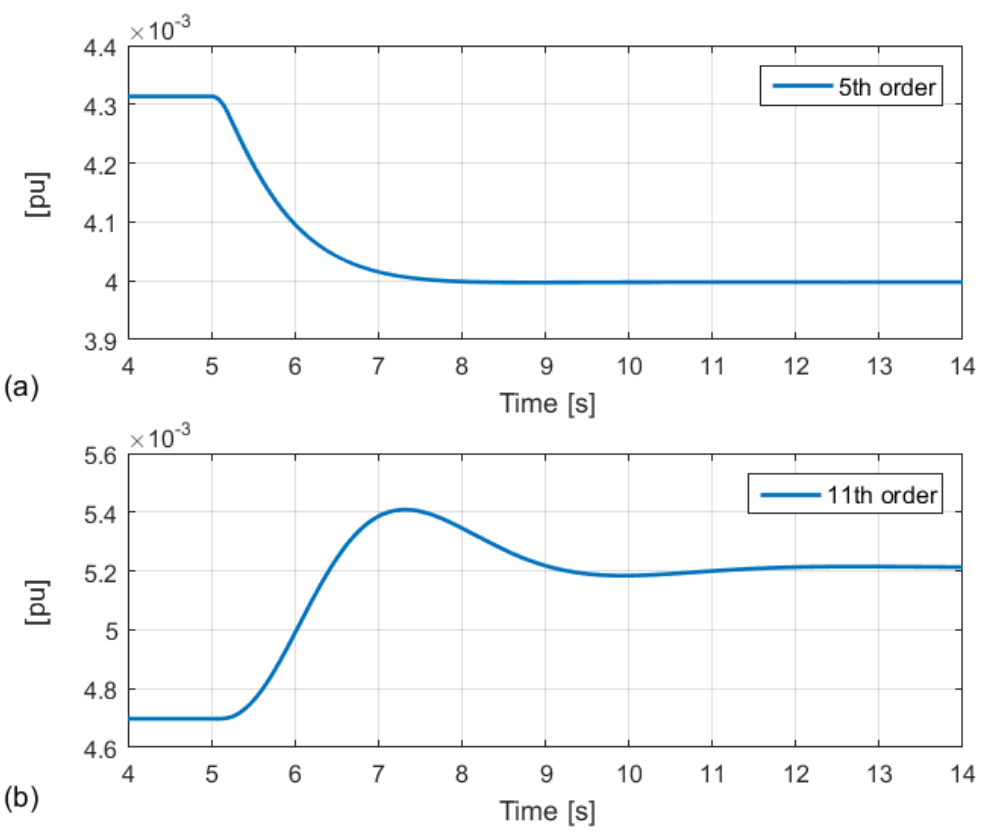

Figure 17. Harmonic voltages at $T_{1}$. (a) $5^{\text {th }}$ order. (b) $11^{\text {th }}$ order.

\section{Conclusion}

This work investigates the amplification of the harmonic voltage distortion due to the background harmonics in the grid at two different buses in a test WPP model. The effect of ideal resistive compensation is numerically analysed and then corroborated using harmonic propagation studies. Afterwards, a time domain simulation is used to include the validate the performance of this scheme including the bandpass filters for the extraction of harmonic voltage components.

The resistive compensation is realized using a STATCOM, which emulates the resistive behavior for the selected harmonic orders. Since the STATCOM controller determines the harmonic current references, its effective resistance can be adapted dynamically in real time. Harmonic resistive compensation has the following salient features:

- It can attenuate the harmonic voltages at its own bus, that is bus $T_{2}$.. Since the WPP has a radial network, the harmonic voltage level gets attenuated downstream from the point of compensation, i.e. at the buses $T_{3}$ and $T_{4}$.

- The attenuation at remote buses upstream from the point of compensation is not guaranteed. Rather, in some cases, there may be an amplification of harmonic distortion levels. In the test system, the $5^{\text {th }}$ and $13^{\text {th }}$ orders were attenuated while there was an amplification for the $7^{\text {th }}$ and $11^{\text {th }}$ orders at the bus $T_{1}$. Therefore, all different scenarios should be evaluated to ensure that there is no undue amplification at the PCC and other buses upstream.

- This method is found to be stable for all values of the emulated resistance as per the Nyquist stability criterion.

Acknowledgments: This work is supported by Energinet.dk through the project "Active filter functionalities for power converters in wind power plants" (ForskEL program, PSO-2014-1-12188). The publication fee is covered by Aalborg University.

\section{Bibliography}

1. Ackermann, T., Transmission Systems for Offshore Wind; John Wiley Sons, Ltd, 2005; chapter 22, pp. 479-503

2. Zhang, S.; Jiang, S.; Lu, X.; Ge, B.; Peng, F.Z. Resonance issues and damping techniques for grid-connected inverters with long transmission cable. Power Electronics, IEEE Transactions on 2014, 29, 110-120. 
3. Chaudhary, S.K.; Lascu, C.V.; Hoseinzadeh, B.; Teodorescu, R.; Kocewiak, L.; Sørensen, T.; Jensen, C.F. Challenges with Harmonic Compensation at a Remote Bus in Offshore Wind Power Plant. IEEE International Conference on Environment and Electrical Engineering (EEEIC 2016) 2016, pp. 1-5.

4. Bradt, M.; Badrzadeh, B.; Camm, E.; Mueller, D.; Schoene, J.; Siebert, T.; Smith, T.; Starke, M.; Walling, R. Harmonics and resonance issues in wind power plants. Transmission and Distribution Conference and Exposition (T\&D), 2012 IEEE PES. IEEE, 2012, pp. 1-8.

5. IEEE Recommended Practices and Requirements for Harmonic Control in Electrical Power Systems. IEEE Std 519-1992 1993.

6. Electromagnetic Compatibility (EMC) - Part 3-6: Limits - Assessment of emission limits for the connection of distorting installations to MV, HV and EHV power systems. IEC Standard 61000-3-6 2008.

7. Electricity Association. Planning Levels for Harmonic Voltage Distortion and the Connection of Non-linear Equipment to Transmission Systems and Distribution Networks in the United Kingdom, 2001.

8. Kocewiak, Ł.; Øhlenschlæger Kramer, B.; Holmstrøm, O.; Jensen, K.; Shuai, L. Active filtering application in large offshore wind farms. in Proc. of The 13th International Workshop on Large-Scale Integration of Wind Power into Power Systems as well as Transmission Networks for Offshore Wind Farms, Energynautics GmbH, 11-13 November 2014, Berlin, Germany., 2014, pp. 11-13.

9. Hoseinzadeh, B.; Bak, C.L. Admittance Modeling of Voltage and Current Controlled Inverter for Harmonic Instability Studies. PES General Meeting Conference Exposition, 2016 IEEE 2016, pp. 1-5.

10. Gustavsen, B.; De Silva, H.J. Inclusion of rational models in an electromagnetic transients program: Y-Parameters, Z-Parameters, S-Parameters, transfer functions. IEEE Transactions on Power Delivery 2013, 28, 1164-1174.

11. Akagi, H.; Fujita, H.; Wada, K. A shunt active filter based on voltage detection for harmonic termination of a radial power distribution line. IEEE Transactions on Industry Applications 1999, 35, 638-645.

12. Badrzadeh, B.; Gupta, M.; Singh, N.; Petersson, A.; Max, L.; others. Power system harmonic analysis in wind power plantsPart I: Study methodology and techniques. Industry Applications Society Annual Meeting (IAS), 2012 IEEE. IEEE, 2012, pp. 1-11.

(c) 2017 by the authors. Licensee Preprints, Basel, Switzerland. This article is an open access article distributed under the terms and conditions of the Creative Commons by Attribution (CC-BY) license (http://creativecommons.org/licenses/by/4.0/). 